\title{
¿Cuánto asustó la pandemia COVID -19 en Perú? Como enfrentó la Carrera de Estomatología este reto
}

\author{
How much did the covid -19 pandemic scare in Peru? How the Stomatology Career faced this challenge.
}

\section{Fredy Gutiérrez-Ventura ${ }^{1, a}$}

En Perú, el viernes 13 de marzo del 2020, cuando escuchamos el anuncio presidencial por primera vez que indicaba que toda la población debería confinarse en sus domicilios a partir del lunes 16 para evitar los contagios con el virus del COVID-19, pensamos que sólo se postergarían las actividades académicas por dos semanas. Realmente fue una situación de incertidumbre difícil de aceptar. Todos, docentes, estudiantes y administrativos entramos en franca preocupación. Esperamos, por lo tanto, 15 días para retornar a las clases presenciales; sin embargo, cuando el presidente anunció otro confinamiento por 15 días más, sabíamos que, quienes teníamos la responsabilidad de afrontar esta terrible pandemia, debíamos diseñar estrategias de sobrevivencia académica. A pesar de no tener apoyo financiero interno ni externo, con el agravante de ser una institución privada que no recibe apoyo estatal ni de otra índole, debemos pensar en los estudiantes, pues la pandemia no debe truncar sus sueños, ni la Facultad de Estomatología de la Universidad Peruana Cayetano Heredia FAEST-UPCH debe dejar de enseñar, actividad principal que desarrolla desde su fundación.

Esa era la realidad que tuvimos que aceptar. El confinamiento inició el 16 de marzo y el 17 iniciamos la capacitación a los docentes en el uso de las diferentes herramientas virtuales y aplicativos como zoom, además de la plataforma EVA (Moodle). Nuestra sorpresa fue mayor cuando la mayoría de docentes rápidamente tomó la decisión de capacitarse, esfuerzo que las autoridades felicitaron, al ver a docentes de distintas edades a una sola voz adecuándose a la nueva realidad: La enseñanza virtual o vía remota. Mayor fue la sorpresa cuando se pensó que, al inicio, sólo tomarían la capacitación los docentes jóvenes, hipótesis equivocada, ya que docentes de bastante experiencia estuvieron en primera línea; durante el primer confinamiento se dio la capacitación y también se realizó el piloto que se validó con el dictado de las clases.

Aunque los profesores todavía teníamos la esperanza de que pronto volveríamos a las clases presenciales, luego de conocer la tercera quincena de confinamiento entendimos que la educación virtual había llegado para quedarse por mucho más tiempo, así que en reuniones virtuales con los docentes y estudiantes concluimos que había que fortalecer este nuevo método de enseñanza impuesto por la circunstancia.

Cabe mencionar que la Facultad de Estomatología desde el año 2005 ya ofrecía educación semipresencial en el curso de anatomía y en la especialidad de Radiología Bucal y Maxilofacial desde 2007, usando la metodología de clase invertida o Flipped Classroom. Esta experiencia fue muy importante, porque algunos docentes ya tenían 
conocimiento de la metodología de enseñanza, lo que ayudó bastante en la adecuación de la enseñanza virtual en las nuevas circunstancias.

Ante algunas dificultades que los docentes presentaron al momento de capacitarse, pensamos que eso no sucedería con los estudiantes porque son los que están actualizados en el manejo del internet y, además, tienen la ventaja al usar recursos digitales, por lo que se adecuarían rápidamente; sin embargo, la sorpresa fue que ellos también tuvieron dificultades para adecuarse al nuevo estatus académico, debido a que hacen uso frecuente de algunos aplicativos populares mas no de la mayoría de aplicativos académicos.

También, como institución, encontramos otras dificultades que no necesariamente dependían de la universidad, debido a que nadie estuvo preparado para la emergencia sanitaria; los domicilios de cada uno se convirtieron en aulas de clases de primaria, secundaria, universitaria y centros de trabajo, todo en un solo espacio porque muchas familias tienen entre sus miembros estudiantes de los distintos niveles educativos, padres que iniciaron sus trabajos vía remota (teletrabajo), entonces el caos se trasladó a los hogares, familias que no habían programado el número de computadoras por cada integrante, el nivel de internet deficiente en cada domicilio, familias que viven en departamentos pequeños con un gran número de miembros, a esto se sumó un buen número de padres de familia que perdieron su trabajo por la pandemia, por lo tanto sus ingresos económicos disminuyeron. Adicionalmente, se incrementó el nivel de contagio del virus COVID-19 en la familia, amigos y vecinos, así como la pérdida de algunos de sus miembros que eran el soporte de la familia, emergieron una situación que agravó el estado anímico y académico de los estudiantes.

Cuando todo nos hacía pensar que por todas las dificultades antes mencionadas en el primer semestre habría una deserción masiva, el índice de deserción de nuestros estudiantes fue mínimo al matricularse en el segundo semestre. Al realizar un breve análisis del porqué de la buena respuesta de los estudiantes y padres de familia a pesar de las circunstancias, la respuesta fue que las decisiones que tomaron las autoridades temporalmente por el periodo de la emergencia sanitaria fueron las adecuadas, como por ejemplo, se flexibilizó el plan de estudios, se quitaron temporalmente los pre-requisitos, se identificó la situación geográfica de los estudiantes, se apoyó con líneas de internet en lugares de difícil acceso, las clases virtuales se colgaron en la plataforma EVA, se utilizó el aplicativo de Anatomía Visible Body, se brindó acceso de la historia clínica virtual a la que antes solo se podía acceder desde la clínica dental, se aprovecharon los casos clínicos antiguos que ya estaban en la Historia Clínica para utilizar como método de casos, se estableció el convenio con la Universidad CES de Colombia para adquirir simuladores maquetas diseñadas con piezas dentarias para cada especialidad, que se constituyó en un gran apoyo para las prácticas de laboratorio virtual, también entre el primer y segundo semestre se realizó una feria de instrumentales y materiales dentales donde los estudiantes adquirieron lo necesario para realizar sus prácticas de laboratorio.

El COVID-19 trajo consigo desorientación en los estudiantes y sus familias, por lo que la facultad reforzó mediante docentes tutores, uno por cada año, y un psicólogo que estuvo apoyando y monitoreando constantemente, comunicándose con los docentes y coordinadores de cada curso, también se tuvo en cuenta las dificultades epidemiológicas de cada familia, desde el punto de vista médico se coordinó con la clínica Centro Renal y Oncológico (CREO), la cual ofreció tarifas preferenciales a estudiantes y familiares para hacer diagnóstico de COVID-19 mediante pruebas rápidas y tomografías de pulmón.

Una vez más, podemos decir que el ciudadano peruano es más fuerte ante las dificultades, y siempre tendrá una solución para un problema. Por eso nuestra felicitación a esos heroicos padres de familia que confían la educación de sus hijos en nuestra Facultad, confianza que valoramos, docentes y autoridades, por eso siempre estamos en la búsqueda constante de innovación en estomatología. En estos momentos tenemos estudiantes que han retornado a sus hogares y muchos están recibiendo las clases desde las regiones del interior del país y otros desde el extranjero, cada uno en sus domicilios al lado de sus familias. 
De las dificultades también se sacan cosas positivas, la pandemia no ha sido la excepción porque ha creado una nueva forma de vida y educación, cuando retornemos a la presencialidad, ya no será la misma situación de antes, la historia de la educación ha marcado un hito antes y después de la pandemia, por eso preguntamos: ¿Cuánto asustó la pandemia COVID -19 en Perú? o cuáles fueron las contribuciones del COVID 19 a la educación superior en Estomatología.

\section{Correspondencia:}

Fredy Gutiérrez-Ventura

Correo electrónico: fredy.gutierrez@upch.pe 